\title{
Practicing mundane consumer resistance in the REKO local food system
}

\author{
Hanna Leipämaa-Leskinen \\ School of Marketing and Communication, University of Vaasa, Vaasa, Finland
}

\begin{abstract}
Purpose - This study aims to answer two research questions, namely, what kinds of mundane resistance practices emerge in the local food system and which spatial, material and social elements catalyse the resistance practices.

Design/methodology/approach - The study adopts a post-humanist practice approach and focusses on exploring the agentic capacity of socio-material elements to generate resistance practices. The data were generated through a multi-method approach of interviews, field observations and Facebook discussions collected between 2014 and 2017.

Findings - The empirical context is the rejäl konsumtion local food network in Finland. The analysis presents two types of resisting practices - resisting facelessness and resisting carelessness - which are connected to spatial, material and social elements.

Research limitations/implications - The study focusses on one local food system, highlighting the socio-material structuring of resistance in this specific cultural setting.

Practical implications - The practical implications highlight that recognising the socio-material elements provides tools for better engagement of consumer actors with local food systems.

Originality/value - The study adds to the extant research by interweaving the consumer resistance literature and local food systems discussions with the neo-material approach. The findings present a more nuanced understanding of the ways in which consumer resistance is actualised in a non-recreational, mundane context of consumption. Consequently, the study offers new insights into the agentic socio-material actors structuring the local food system.
\end{abstract}

Keywords Consumer resistance, Local food system, Post-humanist practice approach, Local food consumption

Paper type Research paper

\section{Introduction}

Local food systems are increasingly transforming conventional ways of food distribution. In Finland, the first attempt to organise local food markets through regular direct trading between consumers and farmers emerged in 2013 when a local food system called REKO (the acronym comes from the native words "rejäl konsumtion" meaning "fair consumption") was established. Before that, Finnish local farmers sold their produce irregularly in outdoor marketplaces or through occasional local food rings. Being initiated together with local consumers and farmers, REKO provided a joint effort to support local food production and

(C) Hanna Leipämaa-Leskinen. Published by Emerald Publishing Limited. This article is published under the Creative Commons Attribution (CC BY 4.0) licence. Anyone may reproduce, distribute, translate and create derivative works of this article (for both commercial and non-commercial purposes), subject to full attribution to the original publication and authors. The full terms of this licence may be seen at http://creativecommons.org/licences/by/4.0/legalcode 
QMR 24,3

resist the conventional agro-food system. Thus, REKO is an example of an alternative food system [1] (Michel-Villarrea et al., 2019; Batat et al., 2017; Manna et al., 2016), more specifically one type of a local food system (Crivits and Paredis, 2013).

To date, most of the prior works on local food systems have explored the support side of the topic, addressing why consumers seek to support local farmers and/or the broader goal of pursuing more sustainable food production (Michel-Villarrea et al., 2019). Studies have indicated that consumers may choose locally produced food for a multitude of reasons. Batat et al. (2017), for example, have categorised the reasons for purchasing local food under the label of idiocentric factors (functional capacities, as well as ideology and experiential aspects) and that of allocentric factors (situational, sociocultural and institutional factors). However, this matter also has another side: local food systems enable the practicing of consumer resistance (Kennedy et al., 2018). The resistance side has received much less attention, but a few works have acknowledged that local food systems are developed when consumers (and farmers) become dissatisfied with the mainstream, industrialised and massproduced food system (Thompson and Coskuner-Balli, 2007a; Szmigin et al., 2003).

This study aims to provide further understanding of how resistance emerges within local food systems. Focussing on the non-recreational context, i.e. food consumption, this study explicates the mundane forms of consumer resistance by exploring the reformist and subtle forms of resistance, instead of consumers' intentional and deliberate resisting behaviours (Cherrier et al., 2011; Ulver-Sneistrup et al., 2011; Peñaloza and Price, 1993). Focussing on the mundane practicing of resistance and looking beyond the neo-liberal consumer resistance behaviours (Bettany and Kerrane, 2011), the study uses as its lens a post-humanist practicebased approach. This approach enables focussing on the agentic capacity of material objects to generate socio-material practices (Schatzki, 2001) and to unfold the socio-material structuring of resistance. Thus, this investigation joins the neo-material bundle of consumer studies, which understands local food systems to include many forms of materiality, such as material things, artefacts, infrastructure and technology, besides the socio-cultural meanings related to local food (Schouten et al., 2016).

The study seeks to answer two research questions:

(1) What kinds of mundane resistance practices emerge in the local food system?

(2) Which spatial, material and social elements catalyse the resistance practices?

The study adds to the extant research by interweaving the consumer resistance literature and local food systems discussions with the neo-material approach. This is accomplished with the following steps. Firstly, the study clarifies the previous theorisations of consumer resistance, as well as of local food systems and what kinds of conceptual elements are connected with them. Secondly, it widens the consumer-centric perspective on resistance by shedding light on the socio-material structuring of resistance. Thirdly, it highlights the neglected role of spatial, material and social elements connected to the resistance practices. The paper proceeds as follows. The theoretical underpinnings build on the prior discussions on consumer resistance and local food systems. The methodological section describes the multi-method approach and the findings present two types of mundane resisting practices - resisting facelessness and resisting carelessness - which are performed within REKO and how the varied kinds of sociomaterial elements generate these practices. The paper ends with its conclusions.

\section{Theoretical underpinnings}

From intentional to mundane consumer resistance

Consumer resistance is a well-acknowledged area of research and has attracted consumer researchers ever since the rise of green consumerism and voluntary simplicity movements in 
the 1990s (Witkowski, 2010). Despite the large amount of extant research, the conceptual foundation of consumer resistance is yet to be clarified. In particular, the parallel referencing to consumer resistance, brand avoidance and anti-consumption or combining them (e.g. referring to brand resistance), creates conceptual vagueness. On the other hand, Cherrier et al. (2011) have addressed that conceptual rigorous is not always the best starting point, but suggest that applying several lens may provide a richer understanding for the matter. Accordingly, this section takes a closer look at consumer resistance, covering also parallel concepts insofar as they enable to valorise the nature of mundane resistance.

Although the seminal work by Peñaloza and Price (1993) suggested that consumer resistance may take various forms, ranging from individual to collective and from reformist to radical, a vast majority of works have explored the so-called intentional and even spectacular forms of resistance (Cherrier et al., 2011; Ulver-Sneistrup et al., 2011). That is, most of the prior works have addressed the expressive and deliberate forms of resistance that take place in niche, often recreational markets (Hollenbeck and Zinkhan, 2010; Lee et al., 2009; Bekin et al., 2006; Thompson et al., 2006). Having explored the recreational marketplace contexts, prior studies commonly share the built-in assumptions that view consumer resistance as intentional acts of individuals. However, as Peñaloza and Price (1993) emphasised, intentionality is not a fundamental feature of consumer resistance, but it may emerge in several forms (Cherrier et al., 2011; Strandvik et al., 2013). Lee (2011, p. 1681) and his colleagues underline that consumer resistance is about "consumers opposing the products, practices and partnerships, associated with a structure of dominance". Thus, according to them, consumer resistance may target various facets of dominance, being, however, always concerned with power relations amongst market actors.

The first facet of consumer resistance illuminates consumers' opposing of firms' products and offerings (Lee et al., 2011). Here the intertwined nature of consumer resistance and brand avoidance comes visible, as much of the previous literature has focussed on brand communities, exploring how consumers show resistance towards a particular brand, product or company. Examples of empirical contexts include anti-Starbucks (Thompson and Arsel, 2004), anti-Walmart (Hollenbeck and Zinkhan, 2010) and anti-Nike movements, as well as anti-genetically engineered communities (Kozinets and Handelman, 2004) and even anti-milk movements (Kristensen et al., 2011). There are only a few papers, which have pointed out that brand avoidance may also take less deliberate and more subtle forms, for instance, Strandvik et al. (2013, p. 488) theorise that brand avoidance may range from persistent to temporary and from explicit to latent forms. Even though they recognise the latent forms of brand avoidance, their empirical analysis focus on more explicit forms.

The second facet indicates how consumers may resist companies' practices, which they regard as unethical or manipulative (Lee et al., 2011). Thus, the focus is on how consumers evaluate firms' marketplace actions. To illustrate, Ulver-Sneistrup et al. (2011) explore mundane brand resistance from the perspective of consumer morality. Their findings address the paradoxes of brand resisting, as consumers are not able to escape brands in the commercial markets; instead, they use various practices to bridge the "bad" brand consumption to the "good" brand consumption. In the context of food, Cronin et al. (2014) have explored how hipsters use food to express resistance to the commercial food marketing system. Elaborating on community consumption, they show that the hipster community uses brand choices and brand avoidance when building a collective identity.

Finally, the third facet of resistance - that of partnerships - appears highly relevant as it indicates how consumers can choose to avoid dominating firms, and instead support alternative distribution channels and market systems (Lee et al., 2011). Importantly, it shows that resistance may be expressed through mundane consumption practices, from which 
QMR 24,3

\section{4}

buying local food products is a good example. Local food systems provide one avenue to oppose dominating partnerships in the agro-food system (Thompson and Coskuner-Balli, 2007a; Szmigin et al., 2003), yet their potential to do that is still to be explored. The local food systems are elaborated in the next section.

\section{Overview of local food systems}

Local food systems can be defined as one specific type of alternative food system (MichelVillarrea et al., 2019; Batat et al., 2017). Crivits and Paredis (2013: p. 312) define local food systems broadly as social networks in which shared ethical and moral values and direct contact between the consumer and farmer are central. Prior literature has addressed several types of local food systems, such as farmers' markets, community-supported agriculture models, solidarity purchasing groups, farm shops and cooperatives (a systematic literature review is provided by Michel-Villarrea et al. (2019)). Table 1 illuminates the conceptual analysis of the most typical types of local food systems: farmers' markets and community supported agriculture (CSA). Because the focal case does not fall into any of the given categories, REKO is conceptualised as a local food system that connects actors both in the physical marketplace and in the online forum.

Farmers' markets are the most commonly discussed type of local food systems. McEachern et al. (2010, p. 399) nicely outline the basic idea of farmers' markets:

- It involves directly selling to the consumer by the person who grew, reared or produced the foods.

- It happens in a common facility where the above activity is practiced by numerous farmers selling local produce.

Social proximity is, indeed, probably one of the most characteristic features of farmers' markets (Moore, 2006). From a more ideological perspective, farmers' markets have been defined as a consumption space, where local, moral, ethical and environmental discourses

\begin{tabular}{llll}
\hline Different types of & $\begin{array}{l}\text { Local food systems } \\
\text { Social networks in which shared ethical and moral values and direct contact between } \\
\text { local food systems }\end{array}$ \\
\hline \multirow{5}{*}{ the consumer and farmer are central (Crivits and Paredis, 2013) }
\end{tabular}

Table 1.

Typical characteristics of local food systems
Local food systems

Social networks in which shared ethical and moral values and direct contact between Community-supported CSA is a relationship established between a farm and a supporting community of members (Galt et al., 2019)

Mutual benefits and formal agreements between consumers and farmers and an online forum 
interact with networks of farmers, consumers and institutions (Holloway and Kneafsey, 2000; Moore, 2006). Prior works have addressed why consumers want to support local farmers; they have shown that the motivations are manifold, e.g. because of the sense of community (Megicks et al., 2012; Bingen et al., 2011; Szmigin et al., 2003) or trust relations between farmers and consumers (Moore, 2006).

CSA originates from the USA and represents another type of local food system, in which a farm and a supporting community of members establish a season-long relationship and share financial risks and rewards together (Galt et al., 2019). Similar kinds of models can be found in eat-local movements, which represent a more recent example of how activist consumers promote more sustainable and socially just food practices (Kennedy et al., 2018). Often CSA has been analysed from the viewpoint of ethical consumerism. Thompson and Coskuner-Balli (2007b, p. 275), for example, see CSA as "a form of ethical consumerism organised by a nexus of ideological discourses, romantic idealisations and unconventional marketplace practices and relationships". Thus, what is characteristic about CSA is the mutually bonding relationship between the consumer members and the farmer, whereas in farmers' markets, consumers choose freely how regularly they purchase local food products.

The REKO local food system represents yet another type of local food system. Within REKO, consumers do not make official agreements to order food products from a specific farmer, as in the case of CSA (Galt et al., 2019), nor do they shop totally without any obligations, as in the case of farmers' markets (McEachern et al., 2010). Instead, food purchases are organised through closed Facebook groups, where local farmers announce every week what they have for sale and consumers place their pre-orders. The actual exchange of products takes place once a week in a given location. Hence, REKO's social elements consist of three types of members - consumers, farmers and administrators - who interact in the physical marketplace and on the Facebook groups. The marketplace and Facebook account for the spatial agents of REKO.

In summary, the conceptual analysis shows that prior works have explicated the important role of spatial and social elements in the local food systems, whereas the material things and their agentic capacity have been given a more minor role. A few exceptions are the works of Crivits and Paredis (2013) and Schouten et al. (2016), which address the role of materiality. The current study aims to fill this gap further and explores how the sociomaterial elements generate mundane consumer resistance practices in the context of a local food system. To be able to envision the mundane forms of resistance, the study takes a posthumanist practice approach, which is described next.

\section{Post-humanist practice approach}

Practice approaches share an axiom that practices represent the primary entities of the social world and that society itself is a field of practices (Schatzki, 2001). Hence, practice theory assumes that social reality is continuously constructed in actions, which are tied to understanding symbolic structures of knowledge (Reckwitz, 2002). A practice is defined as a coordinated entity of actions and then carrying out those actions (Schatzki, 2001). Individuals are seen as carriers of practices and thoughts and feelings are situated in those practices (Halkier and Jensen, 2011; Warde, 2005).

There is no univocal understanding of how to define theories of practice (Warde, 2014: p. 7), and there are several different practice-based approaches. This study adopts a posthumanist practice approach to be able to look beyond the active and conscious ways of showing consumer resistance (Bettany and Kerrane, 2011). The post-humanistic practice approach (Schatzki, 2001) helps to shed light on the material side of practicing resistance, more precisely on how materiality, material artefacts and objects reproduce social practices 
QMR 24,3

(Fuentes, 2014). Leaning on this approach, the current analysis focusses on how resistance practices co-emerge and interact with both human and non-human entities fading the neoliberal view of resistance.

There are several ways of delineating practices, and one of the most common categorisations has been developed by Warde (2005). In his categorisation, practices are distinguished from each other with the help of understandings (skills and projects, as well as know-how), procedures (explicit rules, principles and instructions) and engagements (emotionally charged ends and purposes). Distinguishing between the anatomical elements of each of the practices helps to connect them further with consumption moments and objects, as well as with social interaction in these moments (Halkier and Jensen, 2011).

\section{Methodology}

\section{Data generating}

This study explores one local group of the REKO system. The group is located in Vaasa, on the west coast of Finland. REKO Vaasa is one of the two oldest REKO groups in Finland and also one of the largest groups, which is why it serves as a suitable empirical context for this study. In June 2016 (when the field observations were finished), the number of consumer participants in REKO Vaasa was about 9,200 and the number of farmers was between 20 and 30 . It should be noted, however, that the number of paying customers varied according to seasons and holidays, from about 130 orders to 300 orders per food delivery.

The current data were generated through a multi-method approach using three types of qualitative data sets. The most intensive data generation took place 2014-2017, when interviews, field observations and Facebook discussions were collected. The primary data collection began with two expert interviews to uncover the background of REKO. At the same time, the author started to follow discussions in the REKO Vaasa Facebook group to become familiar with the practices and procedures of making food orders and the discussions around the local food issue. The Facebook discussions were followed during the entire data-generation period.

Secondly, several field observations were made, collecting first-hand purchase experiences of REKO food delivery. The field observations took place in 2015 and 2016; the aim was to gain an emic, within group, understanding of the phenomenon. Observations focussed on actors (both human and non-human) and activities (e.g. queuing, chatting, paying and packaging) in food delivery. Thus, the observations were not about following specific people; they aimed to sketch how the system was organised. Aligned with the post-humanist practice approach, special attention was directed to material objects (e.g. products, packages, vehicles, signs and bags) and tangible physical entities (e.g. delivery locations). The field observations include an observation diary and photos, and a few examples are illustrated in Appendix 1.

Alongside the observations, nine consumer interviews were carried out to generate a more in-depth understanding of what kinds of consumers are engaged in the REKO local food system. Most of the interviews were conducted by another member of the research group, but the author was responsible for designing the interview procedure. Appendix 2 provides a list of the informants' pseudonyms and their demographic profiles. The informants were recruited through the REKO Vaasa Facebook group, and most of them were rather active REKO consumers; thus, the more passive views are absent in the current analysis. The interview began by discussing food consumption in general: how the interviewees practice their daily food shopping and make their food buying choices. After that, the informants were asked to talk about their role in REKO Vaasa: how they joined the group, how and why they buy their food from local farmers and how their food shopping practices have changed if they have. The discussion was intended to be as informal as 
possible (Appendix 3 illustrates the interview guide). The interviews lasted from $1 \mathrm{~h}$ to oneand-a-half hours and all of them were audiotaped and later transcribed.

The author announced herself to the local administrators of REKO at the beginning of data generation, as one of the administrators was interviewed as an expert to get an overview of the REKO organisation. As informants were recruited from the Facebook group, the research project was briefly described to them. Otherwise, the author stayed in the background and did not, for example, initiate new discussions; instead, she acted as an "ordinary" consumer who made pre-orders and collected the products in the delivery. The Facebook group is closed, so the local administrators permit consumers and farmers to join the group. This is why Facebook commentaries are not used as data examples but for generating an emic understanding of the phenomenon, and only interviews and observation diary entries are quoted.

\section{Data analysis}

The process of data analysis began by becoming familiar with the data through iterative readings of the material. Attention was first directed towards "both sides of the coin", i.e. what kinds of resisting and supporting practices the REKO consumers engaged in. The analysis developed by moving back and forth between data and theory, and it was soon noticed that the resistance side provided more fruitful insights in light of the extant literature on local food systems and consumer resistance.

After deciding to focus on the resistance side, the analysis was directed to forming the practice categories. At this point, special attention was paid to unfastening the analysis from the individual consumer: practice was used as the unit of analysis and individuals were regarded as carriers of practices (Halkier and Jensen, 2011). When the initial practice entities started to evolve from the raw material, the anatomy of practices was applied as the analytic coding frame (Warde, 2005), connecting each of the practice entities with the understandings, procedures and engagements. After several types of categorisations, two mundane resistance practices were identified, namely, resisting facelessness and resisting carelessness. In the final phase of analysis, both types of resistance practices were reanalysed by connecting them with spatial, material and social elements. In line with the post-humanist practice approach, all of the socio-material elements were regarded as agentic in that they are able to generate consumer resistance practices and are interlinked with meanings, as well as human and non-human entities (Bettany and Kerrane, 2011; Fuentes, 2014).

\section{Findings}

\section{Contextualising the rejäl konsumtion local food system}

This section briefly outlines the contextual background of REKO based on the interview materials gathered for this study. The founder of the idea, Thomas Snellman, is a Finnish organic farmer who has been actively improving local and organic food markets in Finland since the 1990s. During the years, he faced several difficulties when seeking distribution channels for local and organic produce. Then, in 2012, he visited France and familiarised himself with local farmers' markets, as he tells below:

Then a group of people came. The farmer drove up in his car. He opened the boot and put his products on display on a table. Then it was time. Many consumers came, took products, ticked boxes on a form and went on to the next table. And that was the idea ... the seed for REKO. Like this [snaps fingers], it solved all the questions I'd had for fifteen, twenty years - how to get farmers and consumers together.

After his trip, Thomas, along with a few other enthusiastic individuals, adapted the French concept to Finland. In the beginning, the REKO system followed the logic of CSA and 
QMR 24,3

\section{8}

Table 2.

Mundane resistance practices within the REKO local food system worked as a contract-based system in which consumers committed to ordering foodstuffs from a specific farmer. However, after two months, the farmers noticed that the number of customers was large enough and it was agreed that official agreements were no longer required. From the very beginning, food orders were organised in the closed REKO Facebook groups, where farmers announced what they had for sale and consumers placed their orders. The motivation for organising the trade through a Facebook group was to avoid any intermediaries and extra payments, as well as to have a convenient platform to organise the pre-orders of food. In practice, a small team of dedicated individuals organise each REKO group without any monetary support. They act as administrators who allow participants, both farmers and consumers, to join the Facebook discussion forum.

To shed more light on the contextual background, Finland has the most clustered food markets in Europe with only three operating food retailers. In 2015, the two dominating domestic food retailers held a total market share of $78.6 \%$, while the share of a German chain was $8.3 \%$ (Vekkilä and Rinne, 2016). At the beginning of 2016, one of the two dominating food retailers bought a smaller food chain, increasing the share of the two main retailers to more than $80 \%$ of the total market. Although there is no general agreement on what is "local food" in Finland, it is often defined as food that is produced, marketed and consumed within a certain region, usually within a province (Finnish Government Resolution, 2013). In line with this, Autio et al. (2003) found out that Finnish consumers understand local food as often similar to regional and national food. The cultural meanings of local food are closely embedded in Finnish consumers' social and historical narratives; most authentic local food is connected with artisanal production.

In light of these findings, it was not a surprise that REKO has grown and expanded. Since its beginning, the whole REKO system has spread exponentially, and nowadays it involves rather significant volumes. In 2019, there were over 200 local REKO groups all over Finland, and the number of REKO members has been estimated to be over 280,000 (Ehrnström-Fuentes et al., 2019). During the past couple of years, REKO has started to expand abroad; in 2019, for example, there were over 120 local REKO groups in Sweden. Other Nordic countries, as well as Italy, Ireland and Canada also have active REKO networks.

\section{Practicing mundane resistance in rejäl konsumtion}

Table 2 shows what kinds of mundane resistance practices emerge in the REKO local food system. Both of the practice entities are elaborated more in-depth below.

\begin{tabular}{ll}
$\begin{array}{l}\text { Socio-material } \\
\text { elements }\end{array}$ & Resisting facelessness \\
\hline Core of resistance & $\begin{array}{l}\text { Mass food production that distorts the } \\
\text { power relations of the agro-food system }\end{array}$ \\
$\begin{array}{l}\text { Procedures (explicit } \\
\text { rules, principles and }\end{array}$ & $\begin{array}{l}\text { Regarding Finnish political directives and } \\
\text { bureaucracy too rigid to enable small food } \\
\text { producers to develop their business }\end{array}$ \\
$\begin{array}{l}\text { Understandings } \\
\text { (skills and projects, as }\end{array}$ & $\begin{array}{l}\text { Knowing how to change the } \\
\text { conventional agro-food system to make }\end{array}$ \\
$\begin{array}{l}\text { Engll as know-how) } \\
\text { (emotionally charged }\end{array}$ & $\begin{array}{l}\text { A strong will to support local farmers; } \\
\text { negative emotions connected to visible } \\
\text { ends and purposes) }\end{array}$ \\
$\begin{array}{l}\text { brand names, bonus systems and } \\
\text { commercialisation }\end{array}$
\end{tabular}

Resisting carelessness

Unethical food consumption that increases harmful consequences to the people and nature

Regarding the conventional agro-food system as dismissing the principles of ethical food consumption

Knowing how to carry out ethical food consumption practices in daily lives

A strong will to be identified as an ethical consumer 
Within the practice of "resisting facelessness", resistance is targeted towards mass food production and traditional distribution channels, in which the big food retailers and corporations dominate the smaller producers. Thus, in the mundane context of a local food system, resistance is not directed towards specific brands; but more generally to the unequal partnerships where big actors dominate in the marketplace (Lee et al., 2011) and how brands engage consumers to the logic of commercialisation (Cronin et al., 2014). Below, one informant describes that she joined REKO because she wanted to be able to buy non-branded food products:

But if this allows us to have an influence on making it easier to buy something that's not been packaged by some company, that would be great. I want to be part of it even just because I want to buy goods without being asked for a bonus card. I hate those huge supermarkets. They are disgusting. You always have to walk through the clothing and toy departments. That also irritates me so much. (Laura)

This finding adds to previous discussions that found ordinary consumers resisting branded products (Cronin et al., 2014; Ulver-Sneistrup et al., 2011; Hollenbeck and Zinkhan, 2010). However, the current analysis also shows that resistance was even more often directed towards the dominance of two big Finnish retailers. Their oligopoly was considered to lower the profit margins of small food farmers, and to be able to resist this kind of power distortion, the carriers of the practice were engaged in REKO:

Well, that's why I've ended up shopping at X. I'm annoyed by the food monopoly of the two biggest chains. This is the only way to vote with my wallet for more competition in the food markets - I think local producers deserve better profits, and I'm happy to pay my share. For instance, at REKO, the price is not the decisive factor, but rather meeting the farmers and talking with them [is]. This makes me feel that the money ends up in the right person's pocket. (Matti)

Indeed, the analysis shows that face-to-face meetings between farmers and consumers empower them both, which is aligned with the claims of the importance of the personal touch and face-work commitment in local food systems (Moore, 2006). However, besides social proximity, the practice of resisting facelessness is tied to the rules and principles of how the conventional agro-food system works. The data show that resistance was directed towards Finnish political directives and bureaucracy, which were too rigid to enable small food producers to develop their business; Finnish legislation is criticised as being too conservative and restrictive for local food marketing and production.

The understandings of this practice include presenting practical solutions for how to make the conventional food system fairer and more socially just. Such solutions involve connecting with the right people, which would make it possible to develop new modes of food production. The current informants discussed, for example, how Swedish consumers support and lobby on behalf of small food producers, using this kind of understanding as a benchmarking example for REKO.

This type of resistance practice illustrates the persistence and empowerment necessary to oppose the dominant agro-food system (Kennedy et al., 2018; Thompson and CoskunerBalli, 2007a). Thus, the engagement of this practice involves a strong will to be a part of the REKO system. In contrast, engagement can be seen in the negative emotions that were attached to supermarkets, bonus systems, visible brand names and overconsumption in general. One informant described the negative emotional connection in the following way:

I think it's nice that there's no brand name on the shopping bags. We get our foods straight from the source, and the farmer gets the money. When you buy something from a store, even if it's produced in Ostrobothnia, it says X [the store's brand] on the package, and that sort of ruins the feeling. And you start thinking, how long has this been sitting in the warehouse? It doesn't feel as fresh in the same way. (Maarit) 
QMR 24,3

Another type of mundane resisting practice is labelled as "resisting carelessness". Within this practice, resistance targets to environmentally harmful and unethical ways of food consumption, such as wasting food or buying fast food, performed by other people. Previously also Cherrier et al. (2011) have addressed that consumer resistance is about protest against other consumers. The carriers of this practice wish to oppose the "careless mass" by making better choices in their own everyday lives, for example, through preparing meals at home using local and organic food:

'Well, I try to use mostly organic food and as little additives as possible. And I use basic ingredients so that I can prepare my meals by myself, then I know what the meal contains.' (Lenita)

The understandings of this practice are tied with the skills and know-how concerning how to carry out ethical food consumption. In this regard, REKO membership was seen as an important way not only to make ethical purchases but also to prevent unnecessary food waste, as the planning and shopping of food groceries is more systematic. The next quote shows how the carriers of the practice uses sensory elements, e.g. smelling and tasting the food, to avoid food waste (Alhonnoro et al., 2020):

'People are really slavish about best-by dates. They throw stuff out when it's one day past the best-by date, and I really can't [. . . I I just don't understand that. You should use common sense: if it smells or tastes bad, then don't eat it.' (Matti)

The procedures of this practice are connected to the idea that the agro-food system dismisses the principles of ethical food consumption, extending the resistance to cover the entire system, not only careless consumers. This also means that the carriers of practice agree that the grass-roots-level daily practices are important in changing the system and that the most harmful act is to stop caring. The carriers of the practice were active on the REKO Facebook group, asking for more information about the production methods and discussing the pricing of the products with the farmers. One interviewee was directly asking the farmer questions about the living conditions and slaughtering of the animals:

- If there is a new product that I would like to try I always write to the farmer first. If they do not answer - and some have not - then I would not buy from them.

- What do you ask them about? Production methods?

- Yes and, for instance, what the animals eat and how they are slaughtered. With respect to meat, both what the animal has eaten and the slaughtering process are pretty important (Tiia).

The engagement of this practice is connected to the strong will to be identified as an ethical consumer and to be able to match moral ideology with moral behaviour (Kennedy et al., 2018; Ulver-Sneistrup et al., 2011; Bekin et al., 2006). Alongside the identification, it was also important for them to differentiate themselves from unethical consumers (Cronin et al., 2014):

'And it could be that you get this feeling that we're the people in the know[... . Well, on the other hand, maybe we move in such circles, so I don't know[. . .] Or maybe I just never see people who [... ] It's been maybe fifteen years since I was at McDonalds. I never eat there, so I never see the kind of people who do. I don't know what a person who eats at McDonalds every day looks like, because it's been fifteen years since I stepped in one of those places [. . . ] You find your own social bubble and think that everyone else is the same as you.' (Petteri) 
Table 3 illustrates, which spatial, material and social elements catalyse the mundane resistance practices.

Spatial elements catalysing the practices are connected with the food delivery locations, their infrastructure and temporality. Within the practice of "resisting facelessness", the traditional marketplace spirit and the nostalgic atmosphere showed agency in their capacity to highlight the real sense of local food to the human actors (Autio et al., 2003). One informant described the direct contact with farmers as "a return to the past (Taina)", Mundane consumer resistance indicating a sharp contrast with conventional modes of retailing. Spatial elements of "resisting carelessness" address the approachability of the delivery locations and their timings. During the observation period, the schedule of food deliveries were pushed back to start at 4:15 PM to make it easier to pick up the products on the way home from work. Delivery places were also planned to be located close to the main work passageways minimising unnecessary driving. One informant tells below how this aspect is important for his everyday life:

'For us, it's great, because we have a child who goes to football practice. After I take him there, I pick up the produce, then go fetch him. [...] I used to buy organic strawberries from Vetolahti these past years, an hour's drive, and it felt strange to be sitting in our old car and expelling so much exhaust. I'd rather shop from a single outlet. In that sense, REKO is excellent.' (Petteri)

Material elements within the practice of "resisting facelessness" included handcrafted packages, personal thank you messages and hard cash. They enabled the doers of the practice to oppose shopping for brand products in supermarkets (Ulver-Sneistrup et al., 2011). One observation diary entry includes a remark, in which a 'thank you message' acts as a social link to the farmer:

'I walked to the XX's farm car, where I asked for one kilo of minced meat. The farmers seemed to remember my name, which was fun. [...] Anyway, I got the meat in a paper package and once again on the top of it was written my name and "Thanks for the order". I said that I was very satisfied with the meat last time, and the farmers started to tell how they made hamburgers with rye bread last weekend and that their children liked those, too. So, for a while we kind of talked about healthy eating.' (Diary)

Similar kinds of material elements were needed to actualise the practice of "resisting carelessness". For instance, fabric bags and cardboard boxes were entities helping to avoid plastic waste. Also, empty egg cartons were recycled from consumers to egg farmers and back to consumers, and shopping lists, as well as fridges and freezers, helped to avoid food waste. Finally, many social elements catalyse mundane resistance practices. In the current

\begin{tabular}{lll}
$\begin{array}{l}\text { Socio-material } \\
\text { elements }\end{array}$ & Resisting facelessness & Resisting carelessness \\
\hline $\begin{array}{l}\text { Spatial } \\
\text { (infrastructure, } \\
\text { temporality...) }\end{array}$ & $\begin{array}{l}\text { Traditional marketplace spirit in the food } \\
\text { delivery }\end{array}$ & $\begin{array}{l}\text { Delivery places are located close to the } \\
\text { main work passageways and scheduled } \\
\text { close to the ending of the working days }\end{array}$ \\
$\begin{array}{l}\text { Material (things, } \\
\text { vehicles...) }\end{array}$ & $\begin{array}{l}\text { Handcrafted packages and signs, personal } \\
\text { thank you messages, hard cash }\end{array}$ & $\begin{array}{l}\text { Fabric bags, cardboard packages, } \\
\text { shopping lists, fridge and freezer at home }\end{array}$ \\
$\begin{array}{l}\text { Social elements } \\
\text { (human actors, } \\
\text { technology...) }\end{array}$ & $\begin{array}{l}\text { Meeting face to face in the food delivery, } \\
\text { open discussion on Facebook, spreading the }\end{array}$ & $\begin{array}{l}\text { Discussing sustainable food consumption } \\
\text { on Facebook, feeling close to other REKO } \\
\text { members }\end{array}$ \\
\hline
\end{tabular}

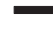


QMR 24,3

\section{2}

context, Facebook stands for a technological venue that has a strong agentic capacity to connect human actors with each other and to enable emotional connections between them, e.g. through sharing food recipes. According to the analysis, Facebook even could change the practice of doing groceries. One informant described how Facebook has made food purchasing more social and peaceful:

'I mean, we have been sitting on a sofa with my wife in the evenings and thinking and looking at the product lists. And then: "Well, do we order these?" "Yes, let's take those." And, "Do we order this?" "Let's take that." I mean, nowadays we never have time for that, we never go to grocery stores together, and if we do, we have so many children with us, and one of us has to watch over them while the other tries to quickly pick the products. So, you are not thinking that much anymore. [REKO] is a much nicer and more peaceful way of shopping, too.' (Petteri)

Social elements are also important catalysts to engage new members in the REKO system. With the help of social connections, the carriers of practice could persuade their friends and acquaintances to purchase ethical food. Sometimes, this was done very openly, as one informant did at the post office, showing a sense of duty to tell ordinary people about REKO:

'On the other hand, I think it's my responsibility to spread the word. For instance, at the post office yesterday, the woman sitting next to me was in a panic because she hadn't managed to buy a Christmas ham. She talked about it, not to me, but to herself, you know, oh woe is me, and so on. So I told her that REKO supplies unfrozen organic hams. She'd never even heard of REKO before. She joined right away, and last night she sent me a message that she'd ordered a ham.'(Tiia)

\section{Discussion and conclusions}

This paper asked how consumer resistance practices are catalysed by socio-material elements within a local food system. Adopting a post-humanist practice approach (Fuentes, 2014; Bettany and Kerrane, 2011; Schatzki, 2001), the study highlights a more comprehensive understanding of the socio-material structuring of consumer resistance.

While the prior discussions on local food systems have advocated for social and spatial proximity between the local farmers and consumers (Moore, 2006), this study shows that various material elements also play an important role in connecting human actors in these systems. This study concludes that besides the shared ideological discourses and the sense of community (Kennedy et al., 2018; McEachern et al., 2010), it is important to recognise the heterogeneous network of human and non-human actors to understand how local food systems operate.

Further, this study adds to the sparse discussions on mundane forms of resistance (Cronin et al., 2014; Ulver-Sneistrup et al., 2011), extending the view of consumer resistance beyond the intentional, radical and expressive forms taking place in niche markets (Strandvik et al., 2013; Hollenbeck and Zinkhan, 2010; Lee et al., 2009). The findings show that mundane consumer resistance not only disputes the dominating roles of brands and the logic of commercialisation but also targets the careless actions of other actors in the markets (Cherrier et al., 2011). Further, looking beyond the individual consumer, the current findings illuminate the previously neglected role of socio-material actors, for example, Facebook, recyclable and personalised packages, as well as nostalgic atmosphere, and their agentic capacity in catalysing mundane forms of resistance in the focal context. These findings also add to the local food system literature, where socio-material elements have been bypassed, with a few exceptions by Crivits and Paredis (2013) and Schouten et al. (2016).

The theoretical implications provide groundings for a bundle of practical implications. Firstly, the recognition of the interplay between human and non-human entities may offer new solutions for better engaging members, especially consumer actors, with the local food 
systems (Galt et al., 2019). This could further help to improve the financial capability of the local farmers and the sustainable transformation of the current agro-food system. Secondly, through valorising the mundane side of consumer resistance, the study broadens the understanding of what consumers oppose in the marketplaces and why. If firms understand the multi-farious reasons behind consumers' protests and that resistance often emerges in subtle actions, they could better develop market offerings, market practices and partnerships that are essentially legitimate for their target consumers.

It is important to acknowledge that not all consumers engage in resistance practices even though they are involved in local (or other types of alternative) food systems. There are many consumers who join local food systems to be able to buy fresh and tasty products or to meet the farmers (Batat et al., 2017). Therefore, the current findings should not be generalised to all types of local food systems, but they illuminate a particular side of the phenomenon, presenting a time- and context-specific understanding of a local food system. Further, the Finnish context, in particular the economic, geographical and cultural conditions, shape the socio-material structuring of the focal system. In future studies, similar kinds of neo-material approaches could be used to explore other newly emerging foodrelated systems, for example, food e-commerce and home food-delivery services.

\section{Note}

1. Local food systems and local food networks are regarded here as interchangeable terms (Michel-Villarreal et al., 2019).

\section{References}

Alhonnoro, L., Leipämaa-Leskinen, H. and Syrjälä, H. (2020), "Distributed agency in food waste: a focus on non-human actors in retail setting", in Närvänen, E., Mesiranta, N., Mattila, M. and Heikkinen, A. (Eds), Food Waste Management: Solving the Wicked Problem, Palgrave Macmillan, Cham, pp. 141-167.

Autio, M., Collins, R., Wahlen, S. and Anttila, M. (2003), "Consuming nostalgia? The appreciation of authenticity in local food production", International Journal of Consumer Studies, Vol. 37 No. 5, pp. 564-568.

Batat, W., Peter, P.C., Vicdan, H., Manna, V., Ulusoy, E. and Hong, S. (2017), "Alternative food consumption (AFC): idiocentric and allocentric factors of influence among low socio-economic status (SES) consumers", Journal of Marketing Management, Vol. 33 Nos 7/8, pp. 580-601.

Bekin, C., Carrigan, M. and Szmigin, I. (2006), "Defying marketing sovereignty: voluntary simplicity at new consumption communities", Qualitative Market Research: An International Journal, Vol. 8 No. 4, pp. 413-429.

Bettany, S. and Kerrane, B. (2011), "The (post-human) consumer, the (post-avian) chicken and the (postobject) eglu”, European Journal of Marketing, Vol. 45 Nos 11/12, pp. 1746-1756.

Bingen, J., Sage, J. and Sirieix, L. (2011), “Consumer coping strategies: a study of consumers committed to eating local", International Journal of Consumer Studies, Vol. 35 No. 4, pp. 410-419.

Cherrier, H., Black, I.R. and Lee, M. (2011), "Intentional non-consumption for sustainability: consumer resistance and/or anti-consumption?”, European Journal of Marketing, Vol. 45 Nos 11/12, pp. 1757-1767.

Crivits, M. and Paredis, E. (2013), "Designing an explanatory practice framework: local food systems as a case", Journal of Consumer Culture, Vol. 13 No. 3, pp. 306-336.

Cronin, J.M., McCarthy, M.B. and Collins, A.C. (2014), "Covert distinction: how hipsters practice foodbased resistance strategies in the production of identity", Consumption Markets and Culture, Vol. 17 No. 1, pp. 2-28. 
QMR 24,3

\section{4}

Ehrnström-Fuentes, M., Jauho, M. and Jallinoja, P. (2019), "Perceptions and experiences of sustainability among producers in the REKO alternative food network in Finland", Sociologia, Vol. 56 No. 4, pp. 401-419.

Finnish Government Resolution (2013), "Local food-but of course! Government programme on local food and development objectives for the local food sector to 2020", available at: http://mmm.fi/ documents/1410837/1890227/LocalFoodButOfCourse.pdf/ef43072b-6700-47ad-af7e-5972e7fe046f (accessed 2 June 2020).

Fuentes, C. (2014), "How green marketing works: practices, materialities, and images", Scandinavian Journal of Management, Vol. 31 No. 2, pp. 192-205.

Galt, R.E., Bradley, K., Christensen, L.O. and Munden-Dixon, K. (2019), "The (un)making of 'CSA people': member retention and the customization paradox in community supported agriculture (CSA) in California", Journal of Rural Studies, Vol. 65, pp. 172-185.

Halkier, B. and Jensen, I. (2011), "Methodological challenges in using practice theory in consumption research: examples from a study on handling nutritional contestations of food consumption", Journal of Consumer Culture, Vol. 11 No. 1, pp. 101-123.

Hollenbeck, C.R. and Zinkhan, G.M. (2010), "Anti-brand communities, negotiation of brand meaning, and the learning process: the case of Wal-Mart", Consumption Markets and Culture, Vol. 13 No. 3, pp. 325-345.

Holloway, L. and Kneafsey, M. (2000), "Reading the space of the farmers' market: a preliminary investigation from the UK", Sociologia Ruralis, Vol. 40 No. 3, pp. 285-299.

Kennedy, E.H., Parkins, J.R. and Johnston, J. (2018), "Food activists, consumer strategies, and the democratic imagination: insights from eat-local movements", Journal of Consumer Culture, Vol. 18 No. 1, pp. 149-168.

Kozinets, R.V. and Handelman, J.M. (2004), "Adversaries of consumption: consumer movements, activism, and ideology", Journal of Consumer Research, Vol. 31 No. 3, pp. 691-704.

Kristensen, D.B., Boye, H. and Askegaard, S. (2011), "Leaving the milky way! The formation of a consumer counter mythology", Journal of Consumer Culture, Vol. 11 No. 2, pp. 195-214.

Lee, M.S.W., Motion, J. and Conroy, D. (2009), “Anti-consumption and Brand avoidance”, Journal of Business Research, Vol. 62 No. 2, pp. 169-180.

Lee, M.S.W., Roux, D., Cherrier, H. and Cova, B. (2011), "Anti-consumption and consumer resistance: concepts, concerns, conflicts and convergence”, European Journal of Marketing, Vol. 45 Nos 11/12, pp. 1680-1687.

McEachern, M.G., Warnaby, G., Carrigan, M. and Szmigin, I. (2010), "Thinking locally, acting locally? Conscious consumers and farmers' markets”, Journal of Marketing Management, Vol. 26 Nos No. 5-6, pp. 395-412.

Manna, V., Emne, U. and Batat, W. (2016), “Alternative food consumption: what is 'alternative??", Marketing Theory, Vol. 16 No. 4, pp. 562-564.

Megicks, P., Memery, J. and Angell, R.J. (2012), "Understanding local food shopping: unpacking the ethical dimension”, Journal of Marketing Management, Vol. 28 Nos No. 3-4, pp. 264-289.

Michel-Villarreal, R., Hingley, M., Canavari, M. and Bregoli, I. (2019), "Sustainability in alternative food networks: a systematic literature review", Sustainability, Vol. 11 No. 3, p. 859.

Moore, O. (2006), "Understanding postorganic fresh fruit and vegetable consumers at participatory farmers' markets in Ireland: reflexivity, trust and social movements", International Journal of Consumer Studies, Vol. 30 No. 5, pp. 416-426.

Peñaloza, L. and Price, L.L. (1993), "Consumer resistance: a conceptual overview”, in McAlister, L. and Rothschild, M.L. (Eds), Advances in Consumer Research 20, Association for Consumer Research, Provo UT, pp. 123-128.

Reckwitz, A. (2002), "Toward a theory of social practices: a development in culturalist theorizing", European Journal of Social Theory, Vol. 5 No. 2, pp. 243-263. 
Schatzki, T.R. (2001), "Introduction: practice theory", in Schatzki, T.R., Knorr Cetina K. and von Savigny E. (Eds), The Practice Turn in Contemporary Theory, Routledge, London, pp. 10-23.

Schouten, J., Martin, D., Blakj, H. and Botez, A. (2016), "From counterculture movement to mainstream market: emergence of the U.S. organic food industry", in Canniford, R. and Bajde, D. (Eds), Assembling Consumption: Researching Actors, Networks and Markets. Routledge, London, pp. 21-31.

Strandvik, T., Rindell, A. and Wilén, K. (2013), "Ethical consumers' Brand avoidance”, Journal of Product and Brand Management, Vol. 22 No. 7, pp. 484-490.

Szmigin, I., Maddock, S. and Carrigan, M. (2003), “Conceptualizing community consumption: farmer's markets and the older consumer", British Food Journal, Vol. 105 No. 8, pp. 542-550.

Thompson, C.J. and Arsel, Z. (2004), "The starbucks brandscape and consumers' (anticorporate) experiences of glocalization", Journal of Consumer Research, Vol. 31 No. 3, pp. 631-642.

Thompson, C.J. and Coskuner-Balli, G. (2007a), "Countervailing market responses to corporate cooptation and the ideological recruitment of consumption communities", Journal of Consumer Research, Vol. 34 No. 2, pp. 135-152.

Thompson, C.J. and Coskuner-Balli, G. (2007b), "Enchanting ethical consumerism: the case of community shared agriculture”, Journal of Consumer Culture, Vol. 7 No. 3, pp. 275-303.

Thompson, C.J., Rindfleisch, A. and Arsel, Z. (2006), "Emotional branding and the strategic value of the doppelgänger brand image", Journal of Marketing, Vol. 70 No. 1, pp. 50-64.

Ulver-Sneistrup, S., Askegaard, S. and Brogård Kristensen, D. (2011), "The new work ethics of consumption and the paradox of mundane brand resistance", Journal of Consumer Culture, Vol. 11 No. 2, pp. 215-238.

Vekkilä, J. and Rinne, A. (2016), "Saman pöydän ääressä: Eväitä suomalaisen ruoan tulevaisuuteen", Aula Research Oy, available at: http://view.sok-julkaisut.fi/public_files/users/sokprisma/ publications/ea0e1d053acdaff28323e3095f1854d1/document.pdf (accessed 1 May 2020).

Warde, A. (2005), "Consumption and theories of practice", Journal of Consumer Culture, Vol. 5 No. 2 , pp. 131-153.

Warde, A. (2014), "After taste: culture, consumption and theories of practice", Journal of Consumer Culture, Vol. 14 No. 3, pp. 279-303.

Witkowski, T.H. (2010), "A brief history of frugality discourses in the United States", Consumption Markets and Culture, Vol. 13 No. 3, pp. 235-258.

\section{Corresponding author}

Hanna Leipämaa-Leskinen can be contacted at: hll@univaasa.fi 
QMR

24,3

356

Figure A1.

Photos from REKO

Vaasa delivery
Appendix 1
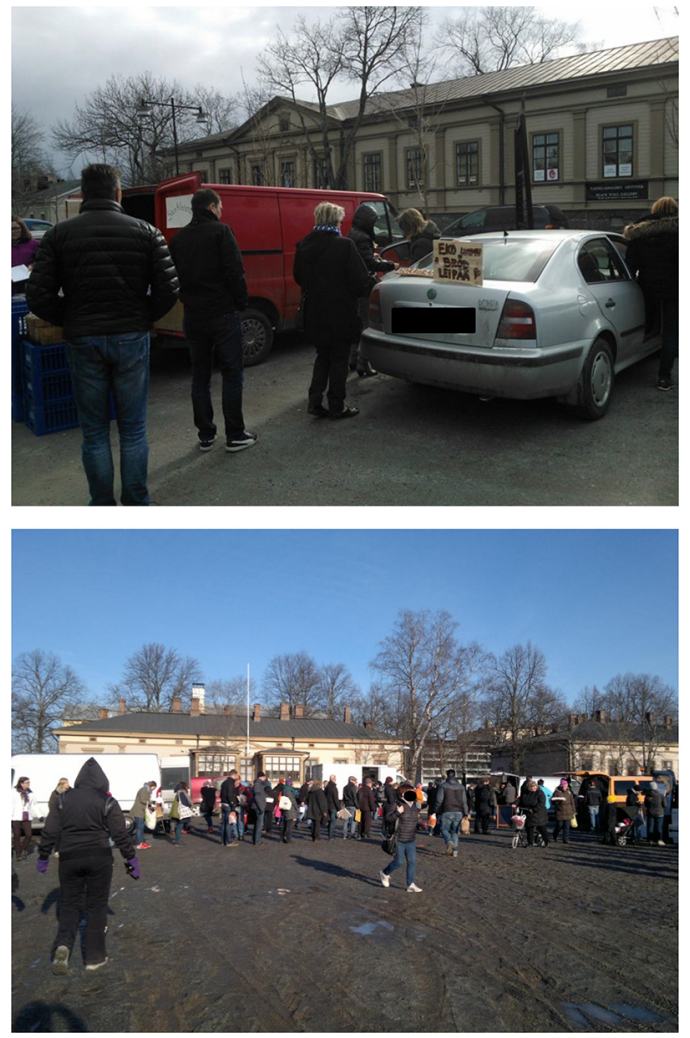


\section{Expert informants}

Thomas

Sofia

Consumer informants

Anna

Matti

Taina

Anni

Laura

Petteri

Tiia

Maarit

Lenita
Role in REKO

resistance

Founder of REKO

Administrator of REKO Vaasa

Family status

Husband and two children Wife and three children Husband and one child Husband, no children Husband and two children Wife and five children Husband and two children Single Single, grown-up children
Table A1.

Informant characteristics

\section{Appendix 3. Interview guide}

(1) Background information

- Name, age, occupation, living area, family status.

(2) Food purchases

- Who makes food purchases in your family and where and when?

- How do you decide what food to buy? (e.g. price, taste, special offers, freshness, convenience, healthiness, responsibility. . .).

- How do you understand local food? How do you understand organic food?

(3) Activities in REKO

- When and why did you join REKO?

- How do you plan your REKO food purchases? What do you think about Facebook as a platform for pre-ordering food?

- What products have you bought/what are the regular products you buy?

- How often do you visit REKO deliveries? What do you think about the delivery situation?

- What do you think about product prices in REKO? Estimate the average price of your REKO food purchases.

(4) Motivations for buying food from REKO

- Why do you buy food from REKO?

- What are your criteria for choosing a farmer?

- Have you changed your food consumption patterns somehow after joining REKO? If so, how?

- Estimate the share of your food purchases from REKO and from other channels?

For instructions on how to order reprints of this article, please visit our website: 